\title{
BMJ Open Cigarette smoking susceptibility among youth alternate tobacco product users: implications of flavoured tobacco from a national cross-sectional Canadian sample (YSS 2012/2013)
}

Leia M Minaker, Alanna Shuh, Nghia Nguyen, Sunday Azagba, Steve R Manske

To cite: Minaker LM, Shuh A, Nguyen N, et al. Cigarette smoking susceptibility among youth alternate tobacco product users: implications of flavoured tobacco from a national cross-sectional Canadian sample (YSS 2012/ 2013). BMJ Open 2015;5: e009549. doi:10.1136/ bmjopen-2015-009549

- Prepublication history for this paper is available online. To view these files please visit the journal online (http://dx.doi.org/10.1136/ bmjopen-2015-009549).

Received 27 July 2015 Revised 26 November 2015 Accepted 27 November 2015

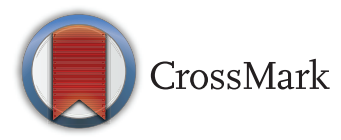

Propel Centre for Population Health Impact, University of Waterloo, Waterloo, Ontario, Canada

Correspondence to Dr Leia M Minaker; Iminaker@uwaterloo.ca

\section{ABSTRACT}

Objectives: Declines in cigarette smoking have been accompanied by increases in alternative tobacco product (ATP) use, particularly among youth. This study examines smoking susceptibility and ATP use in a national sample of Canadian youth.

Methods: Data from grades 9-12 students who participated in the 2012/2013 Youth Smoking Survey, a nationally generalisable sample of Canadian students ( $\mathrm{n}=27$ 404) were used to examine cigarette smoking susceptibility among never smokers $(\mathrm{n}=17396)$. Logistic regression models were used to examine differences in smoking susceptibility by use of flavoured and all ATPs and by sociodemographic and lifestyle characteristics.

Results: Overall, $30 \%$ of Canadian grades $9-12$ never smokers were susceptible to cigarette smoking. Compared to never users, those who had ever tried ATPs (OR=1.96, $95 \% \mathrm{Cl} 1.59$ to 2.42) and those who had ever tried flavoured ATPs (OR=2.20, 95\% $\mathrm{Cl} 1.63$ to 2.96) had significantly higher odds of being susceptible to cigarette smoking.

Conclusions: ATP use is associated with smoking susceptibility among youth never smokers. Findings from this study, along with existing evidence, can be used by policymakers to improve regulation around youth access to ATPs (particularly flavoured varieties).

\section{INTRODUCTION}

Although the prevalence of cigarette smoking has declined, ${ }^{12}$ the use of alternative tobacco products (ATPs) has emerged as a popular trend among North American youth. $^{3-6}$ According to the 2011-2014 National Youth Tobacco Survey, ATPs such as e-cigarettes and hookah were the most commonly used tobacco products among middle school and high school students in the USA, outpacing the use of cigarettes and cigars. ${ }^{7}$ In Canada, about 4 in $10(42 \%)$ of high school students reported ever using any form of tobacco in 2010/2011. ${ }^{8}$ Factors

\section{Strengths and limitations of this study}

- The results of this study are generalisable as the Youth Smoking Survey (YSS) is a large $(n=27404)$, nationally representative survey.

- This study has important policy implications given this new evidence that trying alternate tobacco products is associated with higher odds of cigarette smoking susceptibility among youth.

- Few studies assess the use of multiple varieties of alternative tobacco by high school students.

- This study uses data from a self-reported, crosssectional survey. Therefore, no causal inferences can be made.

- The YSS does not contain nicotine dependence data.

contributing to increasing ATP use include low cost, good taste (particularly of flavoured ATPs) and social acceptability of ATPs. ${ }^{9-15}$ Widespread misconceptions that ATPs are less harmful than cigarettes also contributes to ATP popularity. ${ }^{15} 16$

Among youth, popular varieties of ATPs include smokeless tobacco, cigarillos and cigars, bidis and hookah (or water-pipe). Overall consumption of smokeless tobacco has been increasing over time ${ }^{17}$ despite a low prevalence of use among American youth. ${ }^{18}$ Cigarillo and cigar use is popular among youth in the USA ${ }^{19}$ and Canada. ${ }^{5}$ Among students in New York City, for example, use of cigars and smokeless tobacco increased significantly between 2001 and 2013 while cigarette smoking declined significantly. ${ }^{20}$ From 2006 to 2010 in Canada, current bidi use rose $25 \%$ among youth and increased $50 \%$ among females alone. ${ }^{21}$ Finally, hookah use is increasing in popularity among youth in Canada, ${ }^{321}$ the USA ${ }^{22}$ and worldwide. ${ }^{91123}$ 
ATP use among youth is concerning for two reasons. First, ATPs cause serious health problems, are addictive and can promote or sustain nicotine dependence. $^{11} 11^{21} 24 \quad 25$ Despite widespread belief that ATPs are less harmful than cigarettes, ATPs have serious deleterious effects. ${ }^{24} 2627$ The addition of characterising fruit and candy flavours helps fuel misperceptions around harm associated with ATP use. ${ }^{11}{ }^{28}$ In Canada ${ }^{38}$ and in the USA, ${ }^{19} 2930$ flavoured ATPs are a popular choice among youth and new tobacco users. Second, ATP use may increase individual susceptibility to becoming a cigarette smoker or a polytobacco user, and can diminish chances of smoking cessation success. ${ }^{31}$ The gateway hypothesis (ie, that ATP use can act as a bridge to cigarette smoking), is supported by many studies to date. ${ }^{15} 16253132$ Smoking susceptibility is defined as a lack of a firm decision against smoking, and is a strong predictor of smoking experimentation. ${ }^{33-35}$ Therefore, smoking susceptibility is an important outcome in and of itself. Better understanding smoking susceptibility has the potential to provide direction to tobacco control policies and programmes to prevent smoking initiation. ${ }^{36}$

The purpose of this study was to examine smoking susceptibility and ATP use in a national sample of Canadian grades 9-12 students. Specifically we hypothesise that ATP use will be significantly positively associated with smoking susceptibility among youth never smokers. Second, we hypothesise that flavoured ATP use will also be strongly and positively associated with smoking susceptibility among youth never smokers.

\section{METHODS}

\section{Study design}

The Youth Smoking Survey (YSS) is a biennial, national, provincially generalisable, school-based, paper-andpencil survey that measures knowledge, attitudes and behaviours related to tobacco use among Canadian students. ${ }^{37}$ The target population is grades 6 through 12 students (ages 11-19) at public and private schools $(\mathrm{n}=450)$ in 9 provinces. In the 2012/2013 cycle, those residing in Manitoba, Yukon, Nunavut and Northwest Territories and those living in institutions or on First Nations reserves (representing about 5\% of the Canadian population) were excluded. Surveys were pilot tested to assess student understanding of the questions. Approximately three-quarters (73\%) of respondents participated with passive parental permission, and $27 \%$ participated with active parental permission. The survey was administered during class time, and student participants were not remunerated. Survey development, design, weights, response rates and data collection protocol for the 2008 YSS have been published. ${ }^{37}$ On average during the 2012/2013 YSS wave, $64 \%$ of schools that were approached participated (range, $38 \%$ in Ontario to $96 \%$ in Newfoundland) and $72 \%$ of eligible students completed questionnaires. The 2012/2013 YSS was administered to 47203 youths in grades 6 through 12 attending schools from 9 (of 10) Canadian provinces (of note, in Quebec, secondary school ends at grade 11.) Given the low prevalence of tobacco use among grades 6-8 students, this study uses data from grades 9 to 12 students $(\mathrm{n}=27$ 404). The 2012/2013 YSS survey wave collected data between November 2012 and June 2013 and were analysed in 2015.

\section{Measures and data sources}

Only data from non-smokers (defined as those who answered 'no' to the question, 'Have you ever tried cigarette smoking, even just a few puffs?') who had nonmissing values for the primary outcome of interest (smoking susceptibility) were used in the current study $(n=17$ 396). The dichotomous outcome of interest from the 2012/2013 YSS data set was 'susceptible to smoking' versus 'not susceptible to smoking'. Students who were considered not susceptible to smoking were those who responded 'definitely not' to three questions: 'Do you think in the future you might try smoking cigarettes?'; 'If one of your best friends was to offer you a cigarette, would you smoke it?', and; 'At any time during the next year, do you think you will smoke a cigarette?' Methods of characterising 'susceptible non-smokers' were developed by Pierce $e t a l^{33}$ and are consistent with those used in the Global Youth Tobacco Survey ${ }^{36}$

Two independent variables of interest included 'ever use' of ATPs and of flavoured tobacco products. Ever use of ATPs was derived from students' responses to the question, 'Have you ever tried any of the following? (mark all that apply)' with response options: smoking pipe tobacco; smoking little cigars or cigarillos, smoking cigars (not including little cigars or cigarillos, plain or flavoured); smoking roll-your own cigarettes; smoking bidis (little cigarettes that are hand-rolled in leaves, tied with a string at the ends, and may come in different flavours); using smokeless tobacco (chewing tobacco, pinch, snuff or snus); using a water-pipe (hookah) to smoke sheesha (herbal or tobacco); using blunt wraps (a sheet or tube made of tobacco used to roll cigarette tobacco; I have not tried any of these things. Students who marked the 'I have not tried any of these things' were considered to have never used an ATP. Those with non-missing data who marked at least one of the other options were considered to have ever used an ATP. Ever use of flavoured ATPs was derived from students' response to the question, 'Have you ever used flavoured tobacco products (menthol, cherry, strawberry, vanilla, etc.)?' with response options yes/no. Students who responded yes were considered to have ever used a flavoured tobacco product.

Two other independent variables of interest were past 30 day tobacco use and past 30 day flavoured tobacco use. Past 30 days tobacco use was derived from the question, 'In the past 30 days, did you use any of the following?', with the same response options as those assessing ever use of ATPs (see previous paragraph). Past 30 day flavoured tobacco use was derived from student 
Table 1 Weighted distribution of sociodemographic characteristics, and lifestyle manner among non-smokers (see definition), by level of susceptibility to cigarette smoking-YSS 2012/2013-students grade 9-12

\begin{tabular}{|c|c|c|c|}
\hline \multirow[b]{2}{*}{ Characteristics of survey population } & \multicolumn{3}{|c|}{$\begin{array}{l}\text { Non-smokers (who never tried cigarette smoking, even just a few puffs) } \\
(\mathrm{N}=17 \mathrm{416})\end{array}$} \\
\hline & $\begin{array}{l}\text { Non-susceptible to cigarette } \\
\text { smoking ( } n, \%)\end{array}$ & $\begin{array}{l}\text { Susceptible to cigarette } \\
\text { smoking }(n, \%)\end{array}$ & p Value* \\
\hline \multicolumn{4}{|l|}{ Sociodemographic } \\
\hline \multicolumn{4}{|l|}{ Sex } \\
\hline Female & $6485(48.7)$ & $2672(52.7)$ & \multirow[t]{2}{*}{0.0032} \\
\hline Male & $5810(51.3)$ & 2429 (47.3) & \\
\hline \multicolumn{4}{|l|}{ Grade } \\
\hline 9 & $3503(27.9)$ & 1729 (32.7) & \multirow[t]{4}{*}{$<0.0001$} \\
\hline 10 & $3483(25.4)$ & $1551(28.8)$ & \\
\hline 11 & $3052(25.1)$ & $1128(21.9)$ & \\
\hline 12 & $2257(21.6)$ & $693(16.6)$ & \\
\hline \multicolumn{4}{|l|}{ Provinces } \\
\hline Atlantic & $4279(6.8)$ & $1625(6.6)$ & \multirow[t]{6}{*}{0.1966} \\
\hline Quebec & $1139(15.1)$ & $387(13.7)$ & \\
\hline Ontario & $2062(48.7)$ & 915 (50.9) & \\
\hline Saskatchewan & $1501(2.8)$ & $706(3.0)$ & \\
\hline Alberta & $1498(11.6)$ & $659(11.7)$ & \\
\hline British Columbia & $1816(15.0)$ & $809(14.1)$ & \\
\hline \multicolumn{4}{|l|}{ Ethnicity $\dagger$} \\
\hline White & $8737(64.0)$ & $3523(65.3)$ & \multirow[t]{6}{*}{0.0033} \\
\hline Black & $524(9.0)$ & $182(6.0)$ & \\
\hline Asian & $1460(12.4)$ & $645(13.7)$ & \\
\hline Aboriginal (First Nations, Métis, Inuit) & $521(3.3)$ & $268(3.5)$ & \\
\hline Latin American/Hispanic & $143(1.9)$ & $90(2.9)$ & \\
\hline Other & $842(9.4)$ & $350(8.6)$ & \\
\hline \multicolumn{4}{|l|}{ Living area } \\
\hline Urban & $10256(88.8)$ & $4184(88.4)$ & \multirow[t]{2}{*}{0.6050} \\
\hline Rural & $2039(11.2)$ & 917 (11.6) & \\
\hline \multicolumn{4}{|l|}{ Lifestyle characteristics } \\
\hline \multicolumn{4}{|l|}{ Overall self-esteem score $\dagger$} \\
\hline Less than median (score $\leq 8)$ & $3735(28.4)$ & $2318(43.1)$ & \multirow[t]{3}{*}{$<0.0001$} \\
\hline Median to $<90$ centile (score 9-11) & $6400(53.5)$ & $2258(45.7)$ & \\
\hline 90 centile and above (score 12 up) & $2126(18.1)$ & 509 (11.2) & \\
\hline \multicolumn{4}{|l|}{ Weekly spending money $\dagger$} \\
\hline No money & $2257(24.9)$ & $816(22.7)$ & \multirow[t]{4}{*}{0.0312} \\
\hline$\$ 1-10$ & $1694(17.8)$ & 753 (17.9) & \\
\hline$\$ 11-40$ & $3129(29.4)$ & 1466 (33.4) & \\
\hline More than $\$ 40$ & 2771 (27.9) & $1042(26.0)$ & \\
\hline \multicolumn{4}{|l|}{ Any family member smoking } \\
\hline No & 7845 (66.7) & $2730(56.4)$ & \multirow{2}{*}{$<0.0001$} \\
\hline Yes & 4246 (33.3) & $2245(43.6)$ & \\
\hline \multicolumn{4}{|l|}{ Number of closest friends smoking $†$} \\
\hline No & $8893(79.7)$ & $2947(66.7)$ & \multirow[t]{3}{*}{$<0.0001$} \\
\hline One friend & $1108(9.4)$ & $641(12.0)$ & \\
\hline 2 friends or more & $1333(10.9)$ & $971(21.3)$ & \\
\hline \multicolumn{4}{|c|}{ Risk of having an alcohol or drug-related disordert } \\
\hline No or moderate risk (score of 0 or 1 ) & $10614(89.6)$ & $3823(79.2)$ & $<0.0001$ \\
\hline High risk (score of 2 to 6 ) & $1352(10.4)$ & $1131(20.8)$ & \\
\hline
\end{tabular}

${ }^{*}$ Rao-Scott $\chi^{2} p$ value for test of association.

†Per cent missing values are as follows. For ethnicity, 0.6\%; Overall self-esteem score, $0.3 \%$; Weekly spending money, $20 \%$; Family member smoking, 1.9\%; Number of closest friends smoking, 8.6\%; Risk of having an alcohol or drug-related disorder, $2.7 \%$. Weekly spending money was not included in any models because of the high proportion of missing values.

responses to the question, 'In the past 30 days, did you use any of the following flavoured tobacco products?' with response options: menthol cigarette; flavoured little cigar or cigarillo; flavoured cigar; flavoured tobacco in a water-pipe (hookah), and; I did not use any of these things in the past 30 days. Students who marked the 'I 
Table 2 Factors associated with susceptible to cigarette smoking among students who never 'tried cigarette smoking, even just a few puffs'-Logistic regression analyses-YSS 2012-2013-students grade 9-12

\begin{tabular}{|c|c|c|c|}
\hline Factors & OR unadjusted $(95 \% \mathrm{Cl})$ & $\begin{array}{l}\text { OR adjusted }(95 \% \mathrm{Cl}) \\
\text { Model } 1^{*}\end{array}$ & $\begin{array}{l}\text { OR adjusted }(95 \% \mathrm{Cl}) \\
\text { Model } 2 \dagger\end{array}$ \\
\hline \multicolumn{4}{|l|}{ Sociodemographic } \\
\hline Female & $1.18(1.06$ to 1.31$)$ & $1.17(1.05$ to 1.31$)$ & $1.07(0.94$ to 1.21$)$ \\
\hline Male (ref) & 1.00 & 1.00 & 1.00 \\
\hline \multicolumn{4}{|l|}{ Grade } \\
\hline 11 & $1.13(0.94$ to 1.36$)$ & 1.18 (0.98 to 1.42$)$ & $1.28(1.04$ to 1.58$)$ \\
\hline 12 (ref) & 1.00 & 1.00 & 1.00 \\
\hline \multicolumn{4}{|l|}{ Provinces } \\
\hline Atlantic & $0.92(0.82$ to 1.04$)$ & $0.86(0.76$ to 0.97$)$ & $0.78(0.68$ to 0.89$)$ \\
\hline Quebec & $0.87(0.72$ to 1.04$)$ & $0.74(0.62$ to 0.88$)$ & 0.70 (0.58 to 0.85$)$ \\
\hline \multicolumn{4}{|l|}{ Ethnicity } \\
\hline Black & $0.66(0.51$ to 0.84$)$ & $0.65(0.51$ to 0.84$)$ & $0.78(0.58$ to 1.04$)$ \\
\hline Asian & 1.09 (0.94 to 1.26$)$ & 1.11 (0.94 to 1.32$)$ & $1.16(0.96$ to 1.40$)$ \\
\hline Aboriginal (First Nations, Métis, Inuit) & 1.04 (0.82 to 1.32$)$ & 1.04 (0.82 to 1.33$)$ & $0.97(0.74$ to 1.28$)$ \\
\hline Latin American/Hispanic & 1.52 (1.05 to 2.22$)$ & 1.52 (1.04 to 2.22$)$ & 1.48 (0.99 to 2.23$)$ \\
\hline Other & $0.90(0.74$ to 1.09$)$ & $0.93(0.74$ to 1.15$)$ & $1.01(0.80$ to 1.26$)$ \\
\hline White (ref) & 1.00 & 1.00 & 1.00 \\
\hline \multicolumn{4}{|l|}{ Living area } \\
\hline Rural & 1.04 (0.89 to 1.23$)$ & $1.12(0.94$ to 1.34$)$ & $1.15(0.94$ to 1.39$)$ \\
\hline Urban (ref) & 1.00 & 1.00 & 1.00 \\
\hline \multicolumn{4}{|l|}{ Lifestyle characteristics } \\
\hline One friend & $1.54(1.28$ to 1.84$)$ & & $1.37(1.12$ to 1.67$)$ \\
\hline 2 friends or more & 2.33 (1.99 to 2.72$)$ & & 2.01 (1.69 to 2.39$)$ \\
\hline None (ref) & 1.00 & & 1.00 \\
\hline \multicolumn{4}{|c|}{ Risk of having an alcohol or drug-related disorder } \\
\hline High risk (score of 2-6) & $2.27(1.95$ to 2.65$)$ & & 2.20 (1.85 to 2.62$)$ \\
\hline No or moderate risk (score of 0 or 1 ) (ref) & 1.00 & & 1.00 \\
\hline
\end{tabular}

did not use any of these things in the past 30 days' were considered to have not used a flavoured tobacco product in the past 30 days. Students with non-missing data who marked at least one of the other options were considered to have used a flavoured tobacco product in the past 30 days.

Covariates included the respondent's sex (male, female), grade (9-12), province (where the four Atlantic provinces were grouped together because of cultural similarity and relatively small $\mathrm{n}$ ), self-reported race/ethnicity (white, black, Asian, Aboriginal, Latin
American/Hispanic, or 'other'), level of urbanisation (urban, rural), amount of weekly spending money received (no money, less than $\$ 10 /$ week, $\$ 10-40 /$ week, more than $\$ 40 /$ week), whether or not any close relatives smoke (yes, no), and whether any close friends smoke (none, one friend, two or more friends).

Two additional covariates included self-esteem and risk of having an alcohol or drug-related disorder. Self-esteem was included as a potential confounder given the generally negative association between selfesteem and smoking. ${ }^{38} 39$ Self-esteem score was derived 
Table 3 Five comparisons using multiple logistic regressions for the associations, outcome as susceptible to cigarette smoking-YSS 2012/2013-student grade 9-12

\begin{tabular}{|c|c|c|c|}
\hline Outcomes & $\begin{array}{l}\text { Susceptible to } \\
\text { cigarette smoking* } \\
\text { n (\%) }\end{array}$ & $\begin{array}{l}\text { OR crude } \\
(95 \% \mathrm{Cl})\end{array}$ & $\begin{array}{l}\text { OR adjusted } \\
(95 \% \mathrm{Cl})\end{array}$ \\
\hline \multicolumn{4}{|l|}{ Comparison $1(n=17$ 090)† } \\
\hline Never tried cigarette smoking, but ever tried other types of tobacco & $775(45.7)$ & 2.18 (1.84 to 2.59$)$ & 1.96 (1.59 to 2.42$)$ \\
\hline Never tried cigarette smoking, never tried any types of tobacco (ref) & $4220(27.8)$ & 1.00 & 1.00 \\
\hline \multicolumn{4}{|l|}{ Comparison $2(\mathrm{n}=16$ 231)† } \\
\hline Never tried cigarette smoking, but ever tried some flavoured tobacco & $376(47.5)$ & 2.35 (1.84 to 3.00$)$ & 2.20 (1.63 to 2.96$)$ \\
\hline Never tried cigarette smoking, never tried any types of tobacco (ref) & $4220(27.8)$ & 1.00 & 1.00 \\
\hline \multicolumn{4}{|l|}{ Comparison $3(n=16770) \ddagger$} \\
\hline Never tried cigarette smoking, but some flavoured tobacco in past 30 days & $200(51.4)$ & 2.61 (1.81 to 3.77$)$ & 1.69 (1.08 to 2.64$)$ \\
\hline Never tried cigarette smoking, no tobacco in past 30 days (ref) & 4644 (28.9) & 1.00 & 1.00 \\
\hline \multicolumn{4}{|l|}{ Comparison $4(n=1682) \S$} \\
\hline Never tried cigarette smoking, but ever tried some flavoured tobacco & $376(47.5)$ & $1.16(0.85$ to 1.59$)$ & $1.21(0.88$ to 1.67$)$ \\
\hline Never cigarette, never flavoured tobacco, but ever other types of tobacco (ref) & $436(43.8)$ & 1.00 & 1.00 \\
\hline \multicolumn{4}{|l|}{ Comparison $(n=683) \S$} \\
\hline Never tried cigarette smoking, but some flavoured tobacco in past 30 days & $200(51.4)$ & $1.08(0.63$ to 1.85$)$ & $0.93(0.52$ to 1.64$)$ \\
\hline Never cigarette, no flavoured in past 30 days, but ATP in past 30 days (ref) & $153(49.6)$ & 1.00 & 1.00 \\
\hline
\end{tabular}

*Unweighted number and per cent of participants who were classified to be susceptible to cigarette smoking in each group.

†Variables considered as confounders in the final model: gender, grade, ethnicity, overall self-esteem score, family member smoking, number of closest friends smoking and risk of having an alcohol or drug-related disorder.

$\ddagger$ Variables considered as confounders in the final model: gender, grade, family member smoking and risk of having an alcohol or drug-related disorder.

$\S$ Variables considered as confounders in the final model: gender, grade and family member smoking. 
from participant responses to the following three statements: In general, I like the way I am; When I do something, I do it well; I like the way I look. Response options were on a five-point Likert scale ranging from True to False. Scores were summed (responses to each statement were scored from 'True' $=4$ to 'False' $=0$ ) and categorised into three levels of self-esteem: less than median (score $\leq 8$ ), median to less than 90th centile (score 9-11) and 90th centile or above (score 12+). Risk of having an alcohol or drug-related disorder was included as a potential confounder because of the significant association between tobacco use and alcohol and/or illicit drug use among youth. ${ }^{41}{ }^{41}$ Risk of having an alcohol or drug-related disorder was considered dichotomous (less than high risk, high risk), and was derived from participants' yes/no responses to the following questions: 'Have you ever ridden in a car driven by someone (including yourself) who was 'high' or had been using alcohol or drugs?'; 'Do you ever use alcohol or drugs to relax, feel better about yourself, or fit in?'; 'Do you ever use alcohol or drugs while you are by yourself, alone?'; 'Do you ever forget things you did while using alcohol or drugs?'; 'Do your family and friends ever tell you that you should cut down on your alcohol or drug use?'; 'Have you ever gotten into trouble while you were using alcohol or drugs?'. Participants were defined as no/ moderate risk if they answered yes to zero or one of the questions, and participants were defined as high risk if they answered yes to at least two of the questions.

\section{Statistical analysis}

Survey weights were used to adjust for sample selection (school and class levels), non-response (school, class and student levels), and post-stratification of the sample population relative to grade and sex distribution in the total population. Data were weighted so that the variances take account of the sample design. Descriptive statistics were used to show the weighted distribution of smoking susceptibility by sex, grade, geographic region, self-reported race/ethnicity, self-esteem category, weekly spending money, family member smoking, the number of closest friends smoking and the risk of having an alcohol or drug-related disorder. The weekly spending money variable had a high proportion of missing values $(20 \%)$, so was not included in any models. For all other variables, less than $10 \%$ were missing values. Rao-Scott $\chi^{2}$ statistics were applied to generate a $\mathrm{p}$ value for the statistical difference of each association.

To examine smoking susceptibility among neversmokers, two multiple logistic regression models were fitted to examine associations between sociodemographic characteristics and lifestyle manner and odds of having the outcome, using PROC SURVEY LOGISTICS in SAS 9.4 (SAS/STAT software, SAS Institute Inc, Cary, North Carolina, USA). Model 1 included all sociodemographic variables, and model 2 included all sociodemographic and lifestyle characteristics.
To examine differences in smoking susceptibility by ATP use, we separately conducted five nested casecontrol analyses within this survey population. The first case-control analysis compared the outcome among the case group 'Never tried cigarette smoking, but ever tried other types of tobacco' to that of the control group 'Never tried cigarette smoking, never tried any types of tobacco'. The second case-control analysis compared the outcome among the case group 'Never tried cigarette smoking, but ever tried some flavoured tobacco' to that of the same control group. The third case-control analysis compared the outcome among the case group 'Never tried cigarette smoking, but used some flavoured tobacco in past 30 days' to that of the control group 'Never tried cigarette smoking, did not use any types of tobacco in past 30 days'. The fourth and fifth casecontrol analyses aimed to examine the extent to which flavoured ATP use was associated with smoking susceptibility controlling for ATP use. Therefore, the fourth case-control analysis compared the outcome among the case group 'Never tried cigarette smoking but ever tried flavoured tobacco' with the control group 'Never tried cigarettes, never tried flavoured tobacco, ever tried other types of tobacco', and the fifth analyses compared the outcome among the case group 'Never tried cigarettes, but tried some flavoured tobacco in the past 30 days' with the control group 'Never tried cigarettes, no flavoured tobacco in the past 30 days, but tried ATP in the past 30 days.'

All covariates were individually assessed as confounders using the following criteria: (1) how it was associated with the main exposure, (2) how it was associated with the outcome and (3) whether it was theoretically a pathway of disease process. A covariate was included in the final model if it produced a significant association with the outcome with a $p$ value less than 0.05 for any level of the variable. At first, the full models consisted of main exposure, outcome and potential confounders. Assumptions of logistic regression were checked and Goodness-of-fit test was used to check model fit. A backward elimination strategy was employed in order to evaluate each covariate in the presence of others. Potential confounders were removed one at a time if change-in-estimate of effect measure was less than $10 \%$. The final model (reduced model) for each exposure was tailored to include only covariates that appeared to be a confounder in order to avoid over adjustment and a residual confounding effect.

\section{RESULTS}

The weighted distribution of factors associated with smoking susceptibility among non-smokers is presented in table 1 . Overall, $70.2 \%$ of non-smokers were considered non-susceptible to cigarette smoking, and 29.8\% were considered susceptible (data not shown). There were significant differences in susceptibility by gender, grade, self-esteem, weekly spending money, family and 
friends smoking and those at high risk of having an alcohol or drug-related disorder.

Table 2 shows results from the logistic regression analyses that examined factors associated with the odds of being susceptible to cigarette smoking. Females had significantly higher odds of being susceptible to smoking, as did students in grades 9 and 10 relative to those in grade 12. There were no significant differences in smoking susceptibility by region, other than in British Columbia, non-smoking students had significantly lower odds of being susceptible to smoking. Model 2 showed that students with lower self-esteem had significantly higher odds of being susceptible to smoking compared to students with high self-esteem. Students with at least one family member smoking and with at least one friend smoking also had significantly higher odds of being susceptible to smoking compared to students with no family members or friends smoking. Finally, students at high risk of an alcohol or drug-related disorder had significantly higher odds of being susceptible to smoking relative to students with no or moderate risk of having such a disorder.

Results from the five logistic regressions models fit to examine the association between different exposures to 'ever tried other types of tobacco', 'ever tried some flavoured tobacco', 'used some flavoured tobacco in past 30 days' and the susceptibility to cigarette smoking are presented in table 3. After adjusting for confounders, students who ever tried ATPs had significantly higher odds of being susceptible to cigarette smoking ( $\mathrm{OR}=1.91,95 \%$ CI 1.56 to 2.34) compared to students who never tried any types of tobacco. Similarly, students who had ever tried a flavoured ATPs had significantly higher odds of being susceptible to cigarette smoking $(\mathrm{OR}=2.07,95 \% \mathrm{CI}$ 1.54 to 2.78) compared to students who never tried any types of tobacco. The same pattern held for students who tried flavoured tobacco in the past 30 days, with these students being at significantly higher odds of being susceptible to smoking relative to students who had never smoked a cigarettes and had not consumed ATPs in the past 30 days (OR=1.86, 95\% CI 1.25 to 2.77$)$. Students who reported smoking flavoured ATPs ever or in the past 30 days did not have significantly different cigarette smoking susceptibility compared to those who smoked flavoured ATPS ever or in the past 30 days, respectively.

\section{DISCUSSION}

In 2012/2013, almost one-third (30\%) of Canadian grades 9-12 students who never smoked were susceptible to cigarette smoking. Smoking susceptibility among never smokers is significantly higher among those in younger grades, those who have family members or friends who smoke and those who are at high risk of having an alcohol or drug-related disorder. Importantly, never smokers who have ever tried ATPs, and particularly flavoured ATPs, are at significantly increased odds of being susceptible to cigarette smoking.
First, 30\% of Canadian grades 9-12 students were susceptible to smoking in $2012 / 2013$, compared to $12.5 \%$ of never-smoking youth worldwide and $26.5 \%$ of youth in the Americas who were categorised as susceptible to cigarette smoking in the Global Youth Tobacco Survey. ${ }^{36}$ Given that methods of characterising susceptible nonsmokers were almost identical between the Global Youth Tobacco Survey and our survey, it is of concern that Canadian youth appear to be on the high end of the global spectrum in terms of smoking susceptibility. It may be that the high prevalence of cigarette smoking susceptibility is related to the overall low smoking prevalence in Canada. To be considered 'susceptible' to smoking, respondents must report being non-smokers. With a low smoking rate, therefore, the pool of potentially smoking susceptible respondents is larger. The $30 \%$ of susceptible never-smokers in our study is fairly consistent with previous waves of the YSS. For example, in 2006, 28\% of never smoker grades 9-12 students were susceptible to smoking. ${ }^{42}$ Continued efforts to decrease smoking susceptibility and to prevent movement from susceptibility to smoking initiation are required.

Second, smoking susceptibility in our study was significantly associated with female gender, younger grades, parental or peer smoking, low self-esteem and high risk for alcohol or drug-related disorders. Female gender and younger grade has been previously associated with smoking susceptibility in Canada, ${ }^{42}$ although globally, male gender and age have been found to be positively associated with smoking susceptibility. ${ }^{36}$ One potential reason for our discrepant findings with respect to age was that the global survey examined smoking susceptibility among 13, 14 and 15-year olds, whereas we examined smoking susceptibility among grades 9-12 (typically ages 14-18). It may be that students who have never smoked by 12th grade are already very resistant to smoking. Thus, the smoking susceptibility measure (ie, susceptibility among never smokers) created a finding counter to what was found in the global survey. Our findings that family member and close friend smoking are associated with smoking susceptibility are in line with previous research finding that parental and peer smoking is a well-established factor associated with smoking susceptibility. ${ }^{36}{ }^{42}$ Finally, drug and alcohol use have been associated with smoking susceptibility in previous research, ${ }^{42}$ and our findings are consistent with previous studies finding that tobacco use among youth is significantly associated with alcohol and/or illicit drug use among youth. ${ }^{40} 41$

Finally, never smokers who have ever tried ATPs, and particularly flavoured ATPs, are at significantly increased odds of being susceptible to cigarette smoking. This finding is notable given the current policy action on flavoured tobacco in Canada where provincial and federal restrictions on the sale of tobacco with characterising flavours are coming into effect, ${ }^{8}$ the European Union, which aims to ban menthol in $2016,{ }^{43}$ and the USA, where the Food and Drug Administration banned 
cigarettes with characterising fruit, candy and clove flavours in 2009. ${ }^{44}$ This is the first study to the best of our knowledge to find that ATP use, and particularly flavoured ATP use is associated with significantly higher odds of being susceptible to smoking cigarettes among youth who have never tried cigarettes. We found no statistically significant difference in smoking susceptibility between youth who reported using flavoured ATPs and those who reported using ATPs that were non-flavoured, indicating that in this particular (relatively small) sample, users of flavoured ATPs did not have significantly higher odds of smoking susceptibility compared to youth who used non-flavoured ATPs.

This study has several limitations. First, cross-sectional survey data like the YSS data described here do not allow causal inferences to be made. Second, data are self-reported and were not accompanied by biochemical measures of smoking behaviours or tobacco smoke exposure. Third, YSS does not contain nicotine dependence data. Future research should confirm these findings using validated nicotine dependence measures, given that polytobacco use and ATP use may be associated with nicotine dependence irrespective of cigarette smoking status. Fourth, it is possible that unmeasured confounders (eg, teacher's smoking attitudes or behaviours or exposure to tobacco advertising) could have been associated with both ATP use and cigarette smoking susceptibility. Unfortunately the YSS does not collect data on these variables and therefore they were not included in the analyses. Finally, this survey did not contain information on electronic cigarette use, which is a limitation since electronic cigarettes may be considered an important and increasing form of ATP use. ${ }^{45} 46$ In addition, the liquid vaporised by electronic cigarettes is often flavoured, ${ }^{47}$ which has implications for regulation of flavoured ATPs not captured by the current study. Despite these limitations, the results from this large, provincially-generalisable, national study indicate that ATP use is indeed associated with smoking susceptibility, which is of concern given the growing prevalence of ATP use in Canada and globally. ${ }^{235621}$

Findings from this study, along with existing evidence, can be used by policymakers to improve regulation around ATP access among youth and particularly around flavoured ATP use.

Contributors LMM wrote the manuscript, contributed to analyses and incorporated co-authors' edits and feedbacks into the final manuscript version. AS co-wrote the manuscript. NN conducted the analyses. SRM and SA contributed to manuscript writing and provided substantial feedback on drafts. All authors helped to interpret the data and edit the manuscripts. All authors approved the final version of the manuscript.

Funding The Youth Smoking Survey is a product of the pan-Canadian capacity building project funded through a contract between Health Canada and the Propel Centre for Population Health Impact from 2008 through 2011. The YSS consortium includes Canadian tobacco control researchers from all provinces and provided training opportunities for university students at all levels. The views expressed herein do not necessarily represent the views of Health Canada. The Propel Centre for Population Health Impact acknowledges the support of the Canadian Cancer Society (Major Programme Grant \#701019).
Competing interests None declared.

Ethics approval University of Waterloo Human Research Ethics Committee, the Health Canada Research Ethics Board and appropriate school board and public health ethics committees.

Provenance and peer review Not commissioned; externally peer reviewed.

Data sharing statement No additional data are available.

Open Access This is an Open Access article distributed in accordance with the Creative Commons Attribution Non Commercial (CC BY-NC 4.0) license, which permits others to distribute, remix, adapt, build upon this work noncommercially, and license their derivative works on different terms, provided the original work is properly cited and the use is non-commercial. See: http:// creativecommons.org/licenses/by-nc/4.0/

\section{REFERENCES}

1. Reid JL, Hammond D, Rynard VL, et al. Tobacco Use in Canada: Patterns and Trends, 2014 edition. Waterloo, ON: Propel Centre for Population Health Impact, University of Waterloo. http://www. tobaccoreport.ca/2014/

2. Saunders C, Geletko K. Adolescent cigarette smokers' and non-cigarette smokers' use of alternative tobacco products. Nicotine Tob Res 2012;14:977-85.

3. Minaker LM, Shuh A, Burkhalter R, et al. Hookah use prevalence, predictors, and perceptions among Canadian youth: findings from the 2012/2013 youth smoking survey. Cancer Causes Control 2015;26:831-8.

4. Czoli CD, Hammond D, Reid JL, et al. Use of conventional and alternative tobacco and nicotine products among a sample of Canadian youth. J Adolesc Health 2015;57:123-5.

5. Leatherdale ST, Rios P, Elton-Marshall T, et al. Cigar, cigarillo, and little cigar use among Canadian youth: are we underestimating the magnitude of this problem? J Prim Prev 2011;32:161-70.

6. Connolly GN, Alpert HR. Trends in the use of cigarettes and other tobacco products, 2000-2007. JAMA 2008;299:2629-30.

7. Arrazola RA, Singh T, Corey CG, et al. Tobacco use among middle and high school students-United States, 2011-2014. Morb Mortal Wkly Rep 2015;64:381-5.

8. Minaker LM, Ahmed R, Hammond D, et al. Flavored tobacco use among Canadian students in grades 9 through 12: prevalence and patterns from the 2010-2011 Youth Smoking Survey. Prev Chronic Dis 2014;11:E102.

9. Maziak W. The waterpipe: a new way of hooking youth on tobacco. Am J Addict 2014;23:103-7.

10. Prignot JJ, Sasco AJ, Poulet E, et al. Alternative forms of tobacco use. Int J Tuberc Lung Dis 2008;12:718-27.

11. Sutfin EL, Song EY, Reboussin BA, et al. What are young adults smoking in their hookahs? A latent class analysis of substances smoked. Addict Behav 2014;39:1191-6.

12. Eissenberg T, Ward KD, Smith-Simone $S$, et al. Waterpipe tobacco smoking on a U.S. college campus: prevalence and correlates. $J$ Adolesc Health 2008;42:526-9.

13. Roskin J, Aveyard P. Canadian and English students' beliefs about waterpipe smoking: a qualitative study. BMC Public Health 2009;9:10.

14. Rice VH. Water pipe smoking among the young: the rebirth of an old tradition. Nurs Clin North Am 2012;47:141-8.

15. Cobb C, Ward KD, Maziak W, et al. Waterpipe tobacco smoking: an emerging health crisis in the United States. Am J Health Behav 2010;34:275-85.

16. Mzayek F, Khader $\mathrm{Y}$, Eissenberg T, et al. Patterns of water-pipe and cigarette smoking initiation in schoolchildren: Irbid longitudinal smoking study. Nicotine Tob Res 2012;14:448-54.

17. Delnevo CD, Wackowski OA, Giovenco DP, et al. Examining market trends in the United States smokeless tobacco use: 2005-2011. Tob Control 2014;23:107-12.

18. Lee YO, Hebert CJ, Nonnemaker JM, et al. Youth tobacco product use in the United States. Pediatrics 2015;135:409-15.

19. King BA, Tynan MA, Dube SR, et al. Flavored-little-cigar and flavored-cigarette use among U.S. middle and high school students. $J$ Adolesc Health 2014;54:40-6.

20. Elfassy T, Yi SS, Kansagra SM. Trends in cigarette, cigar, and smokeless tobacco use among New York city public high school youth smokers, 2001-2013. Prev Med Rep 2015;2:488-91.

21. Czoli CD, Leatherdale ST, Rynard V. Bidi and hookah use among Canadian youth: findings from the 2010 Canadian youth smoking survey. Prev Chronic Dis 2013;10:E73. 
22. Amrock SM, Gordon T, Zelikoff JT, et al. Hookah use among adolescents in the United States: results of a national survey. Nicotine Tob Res 2014;16:231-7.

23. Akl EA, Gunukula SK, Aleem S, et al. The prevalence of waterpipe tobacco smoking among the general and specific populations: a systematic review. BMC Public Health 2011;11:244.

24. Latimer LA, Batanova M, Loukas A. Prevalence and harm perceptions of various tobacco products among college students. Nicotine Tob Res 2014;16:519-26.

25. Soldz S, Huyser DJ, Dorsey E. Characteristics of users of cigars, bidis, and kreteks and the relationship to cigarette use. Prev Med 2003;37:250-8.

26. Smith SY, Curbow B, Stillman FA. Harm perception of nicotine products in college freshmen. Nicotine Tob Res 2007;9:977-82.

27. Akl EA, Gaddam S, Gunukula SK, et al. The effects of waterpipe tobacco smoking on health outcomes: a systematic review. Int $J$ Epidemiol 2010;39:834-57.

28. Wray RJ, Jupka K, Berman S, et al. Young adults' perceptions about established and emerging tobacco products: results from eight focus groups. Nicotine Tob Res 2012;14:184-90.

29. Oliver AJ, Jensen JA, Vogel RI, et al. Flavored and nonflavored smokeless tobacco products: rate, pattern of use, and effects. Nicotine Tob Res 2013;15:88-92.

30. Giovino GA, Villanti AC, Mowery PD, et al. Differential trends in cigarette smoking in the USA: is menthol slowing progress? Tob Control 2015:24:28-37.

31. Popova L, Ling PM. Alternative tobacco product use and smoking cessation: a national study. Am J Public Health 2013;103:923-30.

32. Jensen PD, Cortes R, Engholm G, et al. Waterpipe use predicts progression to regular cigarette smoking among Danish youth. Subst Use Misuse 2010;45:1245-61.

33. Pierce JP, Choi WS, Gilpin EA, et al. Validation of susceptibility as a predictor of which adolescents take up smoking in the United States. Health Psychol 1996;15:355-61.

34. Jackson C. Cognitive susceptibility to smoking and initiation of smoking during childhood: a longitudinal study. Prev Med 1998;27:129-34.

35. Strong DR, Hartman SJ, Nodora J, et al. Predictive validity of the expanded susceptibility to smoke index. Nicotine Tob Res $2015 ; 17: 862-9$.
36. Veeranki SP, Mamudu HM, Anderson JL, et al. Worldwide never-smoking youth susceptibility to smoking. $J$ Adolesc Health 2014;54:144-50.

37. Elton-Marshall T, Leatherdale ST, Manske SR, et al. Research methods of the youth smoking survey (YSS). Chronic Dis Inj Can 2011;32:47-54.

38. Carters MA, Byrne DG. The role of stress and area-specific self-esteem in adolescent smoking. Aust J Psychol 2013;65: 180-7.

39. Falomir-Pichastor JM, Mugny G, Berent J, et al. Antismoking norm and smokers' antismoking attitudes: the interplay between personal and group-based self-esteem. Eur J Soc Psychol 2013;43:192-200.

40. Leatherdale ST, Burkhalter R. The substance use profile of Canadian youth: exploring the prevalence of alcohol, drug and tobacco use by gender and grade. Addict Behav 2012;37:318-22.

41. White J, Walton D, Walker N. Exploring comorbid use of marijuana, tobacco, and alcohol among 14 to 15-year-olds: findings from a national survey on adolescent substance use health behavior, health promotion and society. BMC Public Health 2015;15:233.

42. Yang WS, Leatherdale ST, Ahmed R. Smoking susceptibility among never-smokers: data from the 2006-07 national youth smoking survey. Can J Public Health 2011;102:254-7.

43. Perry K. Packets of ten cigarettes and menthol flavours banned under new EU rules. The Telegraph 26 February 2014. http://www. telegraph.co.uk/news/health/10664017/Packets-of-ten-cigarettesand-menthol-flavours-banned-under-new-EU-rules.html

44. U.S. Food and Drug Administration. FDA invites public input on menthol in cigarettes. http://www.fda.gov/NewsEvents/Newsroom/ PressAnnouncements/ucm361966.htm. Updated 2013.

45. Reid JL, Rynard VL, Czoli CD, et al. Who is using e-cigarettes in Canada? Nationally representative data on the prevalence of e-cigarette use among Canadians. Prev Med 2015;81:180-3.

46. Czoli CD, Hammond D, White CM. Electronic cigarettes in Canada: prevalence of use and perceptions among youth and young adults. Can J Public Health 2014; 105:e97-102.

47. Lopez AA, Eissenberg T. Science and the evolving electronic cigarette. Prev Med 2015;80:101-6. 